\title{
Qualidade fisiológica de sementes de crambe submetidas à secagem ${ }^{1}$
}

\author{
Physiological quality of crambe seeds submitted to drying
}

\author{
Rute Quelvia de Faria ${ }^{2 *}$, Itamar Rosa Teixeira ${ }^{3}$, Daniel Antonio da Cunha ${ }^{4}$, Jessica Menezes Honorato e Ivano $^{4}$ \\ Alessandro Devilla ${ }^{3}$
}

\begin{abstract}
RESUMO - O crambe apresenta potencial de cultivo para as regiões tropicais, sobretudo, para o Centro-Oeste brasileiro, podendo ser considerada como uma opção à tão limitada lista de espécies disponíveis para a safrinha. Contudo, a expansão da área de cultivo desta Brassicacea somente ocorrerá com o fornecimento de sementes de qualidade, e para isso os conhecimentos sobre os procedimentos de secagem são relevantes. Este trabalho foi realizado com a finalidade de avaliar a qualidade fisiológica de sementes de crambe submetidas à secagem. Para tanto, foram avaliadas sementes com cinco teores de água $(10 ; 12 ; 15 ; 20 ; 22 \%$ b.u), submetidas a cinco temperaturas de secagem do ar (30; 40; 50; 60 e $70{ }^{\circ} \mathrm{C}$ ). Os testes utilizados para análise foram: teste de germinação, primeira contagem da germinação, comprimento de plântulas e condutividade elétrica. Conclui-se que a temperatura entre 40 a $60{ }^{\circ} \mathrm{C}$ propiciaram melhor desempenho fisiológico nos testes de viabilidade e vigor de sementes de crambe. A temperatura de $70{ }^{\circ} \mathrm{C}$ foi prejudicial ao desempenho fisiológico das sementes de crambe. Teores de água acima de $12 \%$ b.u. sob faixas de temperaturas entre 40 a $60{ }^{\circ} \mathrm{C}$, podem interferir positivamente na quebra de dormência das sementes de crambe.
\end{abstract}

Palavras-chave: Crambe. Secagem. Sementes-qualidade.

\begin{abstract}
The crambe shows potential for being grown in tropical regions, especially in the central-west of Brazil, and can be considered as another option on the limited list of species available for off-season farming. However, any expansion of the area used for the cultivation of this Brassicacea, will only take place with the supply of quality seeds, and for that, knowledge of drying procedures are relevant. This study was carried out in order to evaluate the physiological quality of crambe seeds which had undergone drying. To do this, seeds having five different levels of moisture $(10,12,15,20,22 \%$ w.b.) were evaluated, after being subjected to five drying temperatures $(30,40,50,60$ and $70{ }^{\circ} \mathrm{C}$ ). The tests used in the analysis were: germination, first count, seedling length and electrical conductivity. It can be concluded that temperatures between 40 and $60^{\circ} \mathrm{C}$ afforded better physiological performance in the tests of the viability and vigour of the crambe seeds. A temperature of $70{ }^{\circ} \mathrm{C}$ was detrimental to the physiological performance of the seeds. Water content above $12 \%$ w.b. at temperature ranges of between $40-60{ }^{\circ} \mathrm{C}$ can help break the dormancy of crambe seeds.
\end{abstract}

Key words: Crambe. Drying. Seed-quality.

\footnotetext{
*Autor para correspondência

${ }^{1}$ Recebido para publicação em 02/05/2012; aprovado em 20/02/2014

Parte da Dissertação de Mestrado da primeira autora, apresentado ao Programa de Pós-Graduação em Engenharia Agrícola/Universidade Estadual de Goiás/UEG, Unidade de Ciências Exatas e Tecnológicas, Anápolis-GO

${ }^{2}$ Departamento de Engenharia Agrícola, Instituto Federal Goiano, Campus Urutaí, Rodovia Geraldo Silva Nascimento Km 2,5, Urutaí-GO, Brasil, rute.faria@ifgoiano.edu.br

${ }^{3}$ Programa de Pós-Graduação em Engenharia Agrícola, Universidade Estadual de Goiás/UEG, Unidade de Ciências Exatas e Tecnológicas, BR 153, Campus Henrique Santillo, Anápolis-GO, Brasil, 75.132-400, itamar.texeira@ueg.br, devilla@ueg.br

${ }^{4}$ Bolsistas de Iniciação Cientifica PIBIC/CNPq, Universidade Estadual de Goiás, Unidade de Ciências Exatas e Tecnológicas de Anápolis, daniel-tornado@hotmail.com, jessicamenezesh@hotmail.com
} 


\section{INTRODUÇÃO}

O crambe (Crambe abyssinica Hortsh Ex. R. T) é uma cultura tolerante à seca. Nas condições climáticas brasileiras, comporta-se como cultura de outono/inverno, possuindo ciclo de aproximadamente 90 dias (NEVES et al., 2007; RUAS et al., 2010). É uma planta da família Brassicaceae, de origem mediterrânea, sendo normalmente utilizada como forragem para pasto, mas ultimamente tem recebido atenção por parte da pesquisa e agricultores por ser considerada uma das alternativas para produção de biodiesel (TRZECIAK et al., 2008), visto que suas sementes possuem quantidades significativas de óleo, em torno de 40\% (BITTENCOURT, 2010; CÂMARA; HEIFFIG, 2006; SOUZA et al., 2009), e portanto superior ao da soja, que chega ao máximo de $24 \%$. Ademais, o óleo extraído da semente do crambe pode ser utilizado como lubrificante, na fabricação de filmes plásticos, na composição de fármacos, etc. Colodetti et al. (2012) acrescentam que o óleo de crambe não pode ser utilizado para o consumo humano, devido à presença de altos teores de ácido erúcico, um ácido graxo monoinsuturado de cadeia longa. Esse ácido provoca lesões no coração quando presente no organismo humano. Desta forma, este óleo não concorre com óleos destinados ao setor alimentício.

Esta oleaginosa apresenta grande potencial de cultivo em nossas condições, sobretudo, para safrinha na região Centro-Oeste, como vem ocorrendo no Estado do Mato Grosso do Sul (PITOL; BROCH; ROSCOE, 2010), e recentemente no sudoeste goiano, notadamente no pólo agroindustrial Rio Verde-Jataí, onde sua incorporação ao processo produtivo irá acrescentar mais uma opção de cultivo à limitada lista de espécies disponíveis para "safrinha" (BITTENCOURT, 2010). Porém, para que a sua área de cultivo seja aumentada e se tenha produções elevadas, há necessidade do fornecimento de sementes de qualidade superior aos agricultores.

A qualidade da semente é definida como o somatório dos atributos genéticos, físicos, fisiológicos e sanitários que afetam a capacidade de originar plantas de alta produtividade (CARVALHO; NAKAGAWA, 2000; MARCOS FILHO, 2005). O elevado teor de água na semente no momento da colheita acelera processos metabólicos que culminam na deterioração da mesma. Isto impede que elas sejam armazenadas de forma segura, gerando perdas na germinação e vigor. Neste contexto, a secagem dos produtos é o processo mais utilizado para assegurar a qualidade e estabilidade das sementes, considerando que a diminuição da quantidade de água do material reduz a atividade biológica e as mudanças químicas e físicas que ocorrem durante o armazenamento (CORRÊA et al., 2007; RESENDE et al., 2011).

Problemas relacionados ao baixo vigor das sementes de crambe têm sido constatados em trabalhos de pesquisa. Neves et al. (2007), estudaram dois lotes de sementes de crambe submetidos a duas temperaturas de secagem $\left(25\right.$ e $\left.30^{\circ} \mathrm{C}\right)$, e verificaram que as sementes tiveram melhor desempenho quando submetidas à temperatura de $30^{\circ} \mathrm{C}$, porém apresentou baixa porcentagem de germinação em todos os tratamentos, sendo 53\% o melhor resultado obtido. Este baixo percentual de germinação foi confirmado em trabalho conduzido por Ruas et al. (2010), que obtiveram apenas $44 \%$ de viabilidade de sementes de crambe com pericarpo. Contudo, para o caso do crambe podese dizer que as informações sobre os procedimentos de secagem das sementes são recentes e abrangem os aspectos relacionados à cinética de secagem (COSTA et al., 2013; FARIA et al., 2012) e procedimentos de secagem (COSTA et al., 2012; MARTINS et al., 2012), até porque o cultivo da espécie somente agora começa a adquirir relevância nos trópicos. Assim, há necessidade da busca de informações sobre a temperatura ideal de secagem objetivando a produção de sementes com alto padrão de qualidade.

Desta forma este trabalho teve por objetivo averiguar a qualidade fisiológica das sementes de crambe produzidas nas condições edafoclimáticas do cerrado goiano, e submetidas a diversas condições de secagem.

\section{MATERIAL E MÉTODOS}

As sementes de crambe cv. BRS Brilhante produzidas em Rio Verde-GO na safra das "águas" de 2009 foram colhidas manualmente, com teor de água em torno de $22 \%$ (b.u), sendo homogeneizadas e colocadas em sacos de polipropileno de baixa densidade onde permaneceram acondicionadas em freezer, à temperatura em torno de $4^{\circ} \mathrm{C}$, até o momento da secagem.

Objetivando a obtenção de amostras com diferentes teores de água, uma parte das sementes foi colocada em uma bandeja plástica, sem cobertura para que as mesmas perdessem água naturalmente. Este processo foi realizado dentro do laboratório em temperatura ambiente $\left(27^{\circ} \mathrm{C}\right)$, sem ventilação forçada com umidade relativa em torno de $70 \%$.

Empregou-se o delineamento inteiramente casualizado, em esquema fatorial $5 \times 5$, com quatro repetições. Os tratamentos foram constituídos de lotes de sementes de crambe com cinco teores de água $(10 ; 12 ; 15$; $20 ; 22 \%$ b.u $)$, submetidas a cinco temperaturas de secagem do ar $\left(30 ; 40 ; 50 ; 60 ; 70{ }^{\circ} \mathrm{C}\right)$, obtidas num período que compreendeu entre 2 e 24 horas. Os valores do teor de água foram determinados pelo método gravimétrico, utilizando-se a estufa a $105 \pm 1{ }^{\circ} \mathrm{C}$, durante 24 horas (BRASIL, 2009).

$\mathrm{O}$ processo de secagem foi realizado por meio de um secador de leito fixo, horizontal, com ventilação de ar forçada, com três bandejas removíveis, de fundo telado 
(Figura 1). O secador possui um diâmetro de abertura para cada bandeja de $20 \mathrm{~cm}$ para saída de ar quente. A entrada de ar ambiente é controlada com um regulador de fluxo de ar, podendo ser totalmente fechada e aberta até $40 \mathrm{~cm}$ de diâmetro. Sua temperatura pode atingir $120^{\circ} \mathrm{C}$. Cada bandeja possui uma altura de $12 \mathrm{~cm}$, com uma capacidade volumétrica de $3,7 \mathrm{dm}^{3}$. O secador possui $3,8 \mathrm{~m}$ de comprimento, e uma coluna por onde é conduzido o ar quente de 1,3 m de altura. Sobre as bandejas foi distribuída uma camada fina (1,5 cm de espessura) de sementes, sendo previamente retiradas do freezer e permanecendo por pelo menos 40 minutos em bancada, a fim de entrar em equilíbrio com o ar ambiente. A secagem foi conduzida até que as sementes atingissem o equilíbrio higroscópico com as condições do ar de secagem. A redução do teor de água foi monitorada utilizando uma balança analítica, com resolução de $0,01 \mathrm{~g}$. A velocidade do ar foi controlada e mantida constante em torno de $1 \mathrm{~m} \mathrm{~s}^{-1}$, com auxílio de um termo-anemômetro digital da marca Minipa, modelo MDA - II. A temperatura foi monitorada por meio de um termopar localizado na saída do ar de secagem e a umidade relativa do ar ambiente foi medida com um psicrômetro.

Imediatamente à secagem, avaliou-se o potencial fisiológico das sementes por meio dos seguintes testes: Teste Padrão de Germinação - TPG, onde as sementes foram colocadas para germinar em substrato de papel, a $22^{\circ} \mathrm{C}$, sendo realizadas duas contagens das plântulas normais, no $3^{\circ}$ e $7^{\circ}$ dia após o início do teste (BRASIL, 2009); primeira contagem da germinação, avaliada no $3^{\circ}$ dia após a semeadura, computando-se o percentual de plântulas normais; comprimento de plântulas, conduzido em conjunto com a primeira contagem da germinação, medindo-se

Figura 1 - Secador experimental de leito fixo utilizado na secagem das sementes de crambe: vista lateral (A) e vista superior (B)

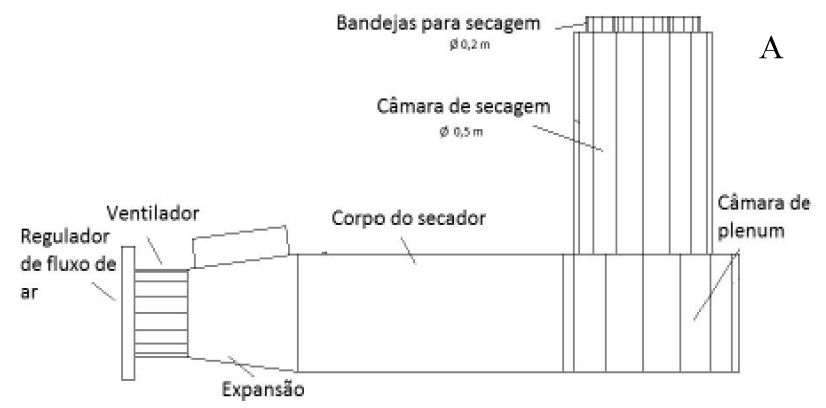

B

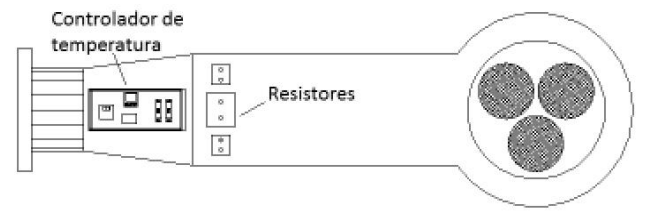

as plântulas normais que germinaram ao $3^{\circ}$ dia, e que atingiram um comprimento da raiz primária, maior ou igual a $1,5 \mathrm{~cm}$, sendo em seguida computada a média do comprimento das plântulas normais, conforme sugerido por Vanzolini et al. (2007); condutividade elétrica, sendo separadas quatro repetições de 50 sementes, pesadas e colocadas em copos plásticos descartáveis, com capacidade de $200 \mathrm{~mL}$; adicionaram-se $75 \mathrm{~mL}$ de água deionizada e foram mantidos por 24 horas em câmara a $25^{\circ} \mathrm{C}$. Após este período determinou-se, a condutividade da solução na qual se encontravam imersas as sementes (VIEIRA et al., 2002). Os resultados foram calculados em $\mu \mathrm{S} \mathrm{cm}^{-1} \mathrm{~g}^{-1}$.

Os dados obtidos foram inicialmente submetidos à verificação da normalidade e homogeneidade por meio dos testes de Lilliefors (SPRENT; SMEETON, 2007) e Cochran/Bartllett (SPRENT; SMEETON, 2007; STEEL; TORRIE; DICKEY, 1997), respectivamente. Posteriormente foi realizada a análise de variância com 5\% de significância para o teste F. Empregouse ainda, o método da superfície de resposta, sendo a escolha dos modelos feita com base na significância do coeficiente de regressão considerando-se o teste $\mathrm{t}$ a $5 \%$ de probabilidade, no coeficiente de determinação e no comportamento biológico. Os cálculos estatísticos foram realizados por meio do Sistema de Análise Estatística Genética (SAEG).

\section{RESULTADOS E DISCUSSÃO}

Os pressupostos para validação da análise estatística avaliados, por meio dos testes de normalidade dos dados e homogeneidade das variâncias foram atendidos (Figura 2; Tabela 1), não havendo, portanto, necessidade de transformação de dados.

Pelo resultado da análise de variância pode-verificar que ao final do procedimento de secagem a umidade de equilíbrio (Ueq), para os tratamentos aplicados, foram de $8 ; 4$ e $1 \%$ b.u., para as temperaturas de $30 ; 50$ e $70{ }^{\circ} \mathrm{C}$, respectivamente, sendo portanto, a Ueq inversamente proporcional à temperatura do ar de secagem.

O número de plântulas normais no TPG proveniente de sementes de crambe submetidas às diversas condições de secagem variou significativamente, tanto nas diferentes temperaturas às quais foram submetidas quanto nos diferentes teores de água na semente, com efeito da interação entre os dois fatores (Tabela 2).

O número de plântulas normais obtidas no teste de germinação apresentou significância para os fatores teor de água (linear) e para a interação temperatura e teor de água. Ajustou-se o modelo de superfície de resposta para o percentual de plântulas normais quantificadas no 
Figura 2 - Valores da normalidade dos dados pelo teste de Lillefors para os dados de germinação (A), primeira contagem (B), comprimento de plântula $(C)$ e condutividade elétrica $(D)$ em sementes de crambe submetidas à diferentes teores de água e temperaturas de secagem. Significativo à 1 e $5 \%$ de probabilidade

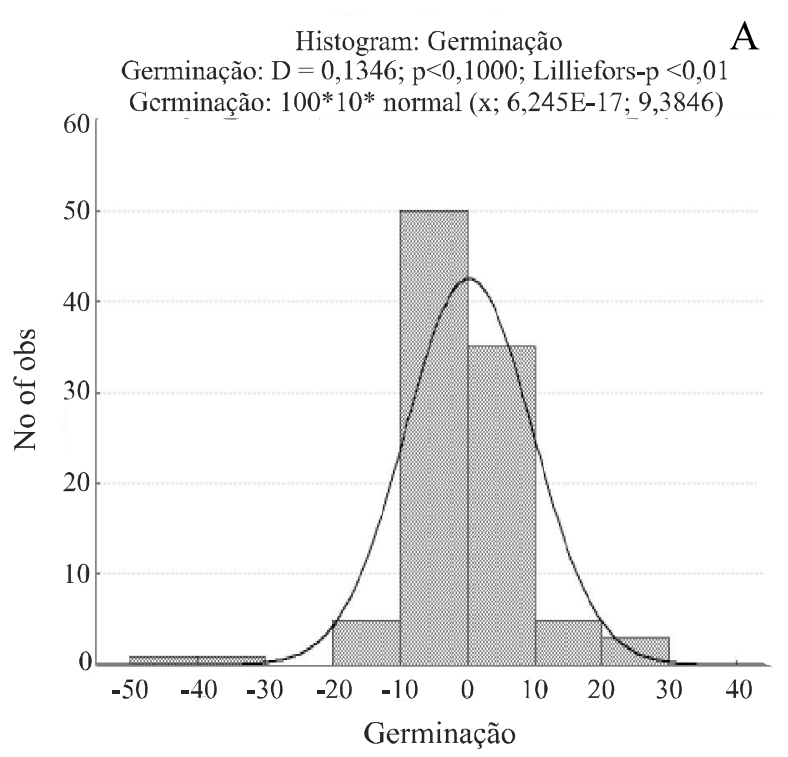

Histogram: Comprimento de Plântulas

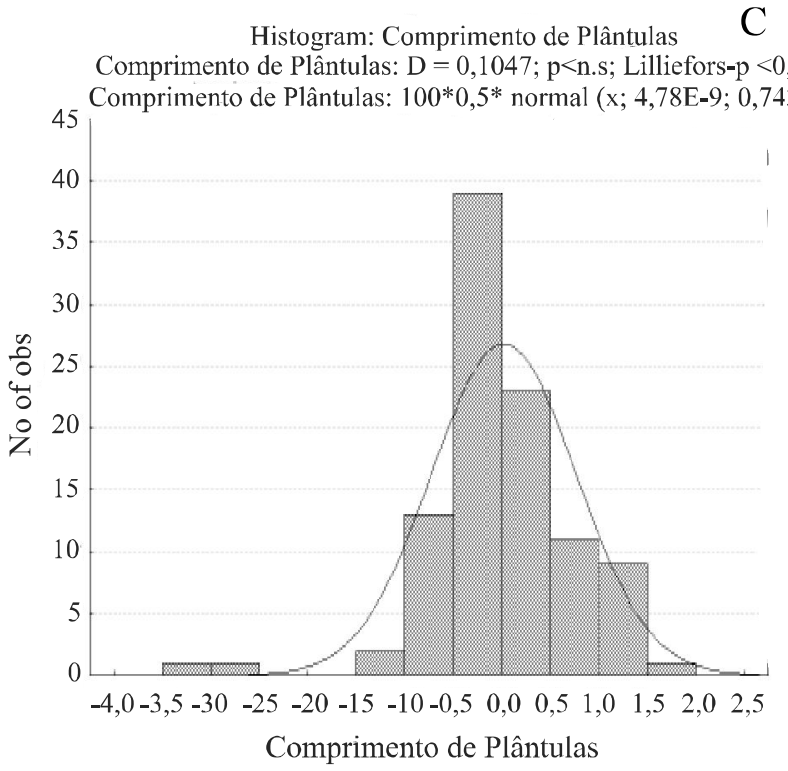

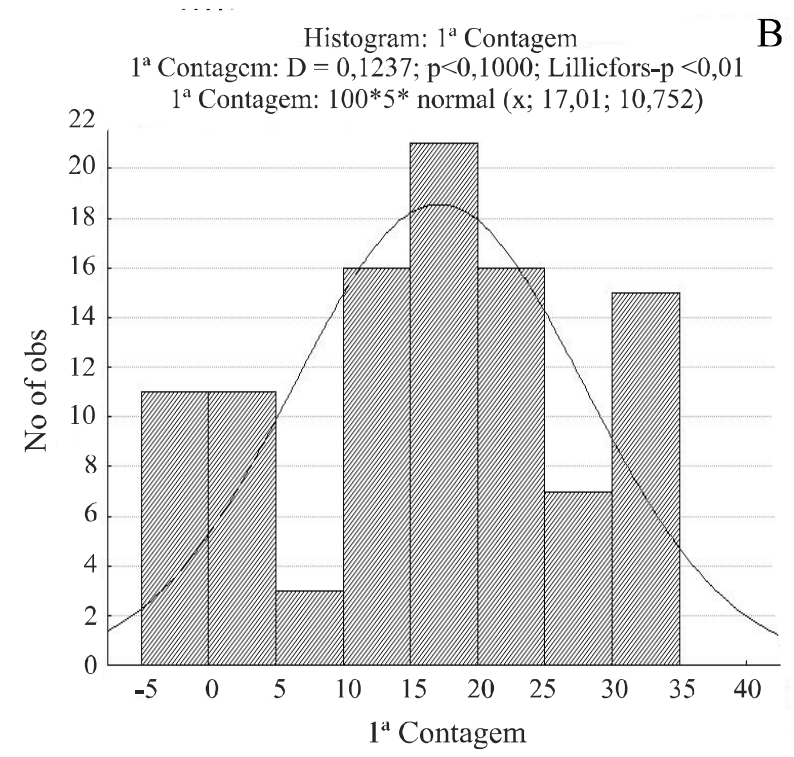

Histogram: Condutividade Elétrica (CE)

Effect: "Temperatura"**"Teor de água". (Plot of with-cell residuals)

$\mathrm{D}$

Condutividade Elétrica (CE): $\mathrm{D}=0,092 ; \mathrm{p}<\mathrm{n}$.s; Lilliefors- $\mathrm{p}<0,05$

Condutividade Elétrica (CE): $100 * 0,5^{*}$ normal $(x ;-2,868 \mathrm{E}-7 ; 8,3864)$

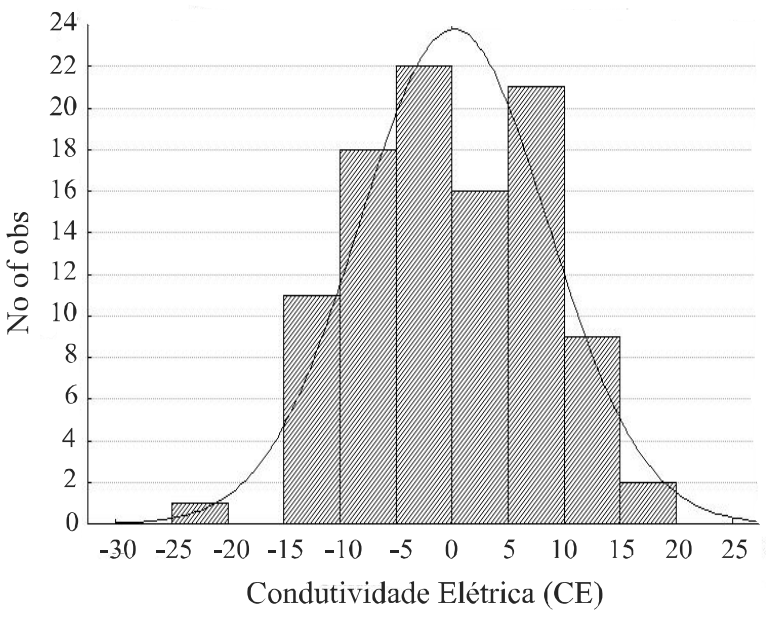

Tabela 1 - Valores da homogeneidade das variâncias pelos testes de Cochran e Bartlett para os dados de germinação (G), primeira contagem $(\mathrm{PC})$, comprimento de plântula $(\mathrm{CP})$ e condutividade elétrica $(\mathrm{CE})$ em sementes de crambe submetidas à diferentes teores de água e temperaturas de secagem

\begin{tabular}{lcc}
\hline \multirow{2}{*}{ Variáveis (testes) } & C & Chi-Sgrx) \\
\cline { 2 - 3 } & Cochran & Bartlett \\
\hline Germinação & $0,13^{\text {ns }}, 01^{\text {ns }}$ \\
Primeira contagem & $0,11^{\text {ns }}$ & $17,19^{\text {ns }}$ \\
Comprimento de plântula & $0,09^{\mathrm{ns}}$ & $21,97^{\mathrm{ns}}$ \\
Condutividade elétrica & $0,12^{\mathrm{ns}}$ & $19,94^{\mathrm{ns}}$ \\
\hline
\end{tabular}

ns - não significativo a $5 \%$ de probabilidade 
Tabela 2 - Resultado da análise de variância referente à porcentagem de plântulas normais obtidas ao teste padrão de germinação - TPG, em função da temperatura do ar de secagem e dos teores de água nas sementes de crambe

\begin{tabular}{lcccc}
\hline \multicolumn{1}{c}{ Fatores } & GL & SQ & QM & F \\
\hline Temp. de secagem (TS) & 4 & 1152,14 & 288,04 & $4,35^{* *}$ \\
Teor de água (TA) & 4 & 918,04 & 229,51 & $3,47^{* *}$ \\
TA X TS & 16 & 4419,56 & 276,22 & $4,18^{* *}$ \\
Resíduo & 75 & 4955,25 & 66,07 & - \\
Total & 99 & 11444,99 & - & - \\
\hline
\end{tabular}

**Significativo a $1 \%$ de probabilidade pelo teste F. C.V. $=7,09$

TPG das sementes de crambe, submetidas às diversas condições de secagem (Figura 3).

Menor percentual de germinação foi constatado nos teores de água mais elevados. Nas sementes que apresentaram teores de água mais baixo houve melhor desenvolvimento das plântulas normais. Observa-se ainda, que para as sementes com teores de água mais altos (acima de $15 \%$ b.u.), a secagem foi mais agressiva à qualidade das mesmas, ocasionando menor percentual de germinação; porém sementes com teores de água abaixo de $15 \%$ apresentaram bom desempenho na germinação, mesmo em temperaturas elevadas, comportamento não esperado.

Pelos resultados obtidos no teste de germinação pode-se dizer que a elevação nas temperaturas acima de $50{ }^{\circ} \mathrm{C}$ e teores de água abaixo de $15 \%$ b.u. propiciaram maiores valores em média do percentual de germinação de sementes de crambe. Este resultado contradiz a literatura que recomenda para secagem de sementes um valor

Figura 3 - Superfície de resposta para o efeito da temperatura de secagem e teor de água em sementes de crambe, no teste de germinação

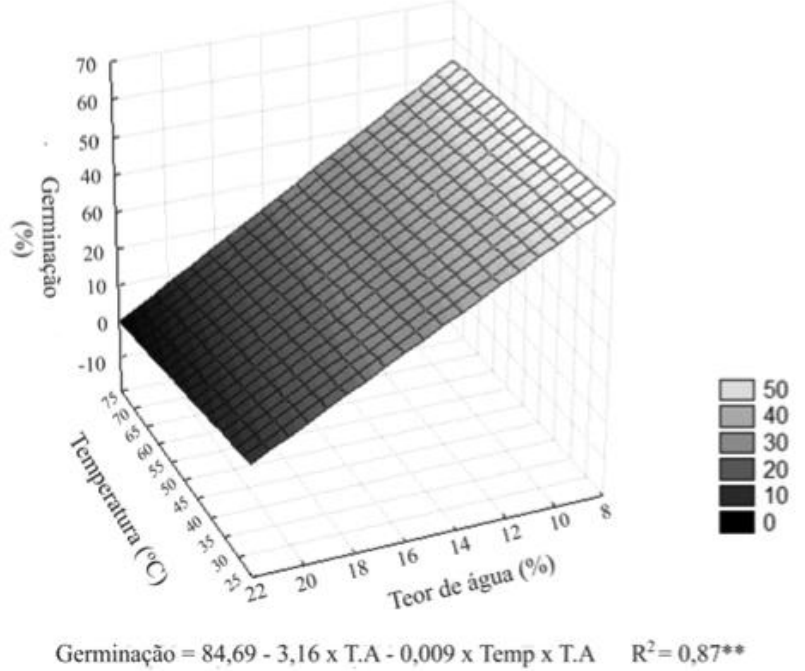

máximo de $42{ }^{\circ} \mathrm{C}$ (KRZYZANOWSKI; VIEIRA; FRANÇA NETO, 1999). Notou-se também que um menor teor de água nas sementes, reduziu os possíveis danos causados durante a secagem.

$\mathrm{O}$ incremento da temperatura teve efeito positivo na germinação de sementes de crambe que apresentaram baixos teores de água. Acredita-se, apesar da escassez de estudos que confirme esta hipótese, que o aumento da temperatura possa influenciar na quebra da dormência em sementes de crambe, conforme constatado em trabalho de Neves et al. (2007), que verificaram ter a temperatura de $35^{\circ} \mathrm{C}$ melhor desempenho na germinação de sementes de crambe quando comparada à temperatura de $20{ }^{\circ} \mathrm{C}$. Contudo, para a temperatura de $70{ }^{\circ} \mathrm{C}$ a germinação foi praticamente nula em todos os tratamentos, com exceção para as sementes com teores de água de $10 \%$ b.u., comportamento que corrobora os resultados obtidos com sementes de crambe submetidas à secagem na mesma temperatura por Costa et al. (2012).

Em geral observa-se, que o baixo percentual de germinação apresentado pelas sementes de crambe se deve a algum tipo de dormência, atribuído a fatores como: dureza do tegumento, regulação hormonal com excesso de ácido abscísico e ausência de giberilina, temperatura extrema ou frio intenso e imaturidade do embrião (MARCOS FILHO, 2005; MARTINS et al., 2012). Costa, Martins e Lopes (2010) também encontraram valores baixos de germinação indicando dormência das sementes recém-colhidas, e corroborando aos resultados aqui encontrados. Em adição, Neves et al. (2007) e Ruas et al. (2010) obtiveram valores de germinação das sementes de crambe bem próximos aos encontrados neste trabalho.

$\mathrm{O}$ resultado do teste de primeira contagem para o número de plântulas normais corrobora ao verificado no teste de germinação, tendo sido detectado efeitos significativos dos tratamentos sobre os fatores em estudo isoladamente e pela interação teor de água x temperatura (Tabela 3).

Considerando que o modelo proposto foi significativo apenas para o comportamento linear da 
Tabela 3 - Resultado da análise de variância referente à porcentagem de plântulas normais obtidas ao teste de primeira contagem do TPG, em função da temperatura do ar de secagem e dos teores de água nas sementes de crambe

\begin{tabular}{lcrcc}
\hline \multicolumn{1}{c}{ Fatores } & G.L & SQ & QM & F \\
\hline Temp. de secagem (TS) & 4 & 10004,6 & 2501,1 & $21,5146^{* *}$ \\
Teor de água (TA) & 4 & 4366,2 & 1091,5 & $9,3893^{* *}$ \\
TS X TA & 16 & 13309,4 & 831,8 & $7,1554^{* *}$ \\
Resíduo & 75 & 8719,0 & 116,3 & - \\
Total & 99 & 36399,2 & - & - \\
\hline
\end{tabular}

**Significativo à $1 \%$ de probabilidade pelo teste F. C.V. $=6,20 \%$

variável teor de água, e para interação linear da temperatura e teor de água, observa-se que o desempenho das sementes reduziu com o aumento do teor de água (Figura 4). Verifica-se ainda, acréscimo do percentual de plântulas normais, mesmo em temperaturas acima de $40^{\circ} \mathrm{C}$, conforme verificado no teste de germinação. Este resultado contradiz a literatura que recomenda para secagem de sementes o valor máximo de $42{ }^{\circ} \mathrm{C}$ (KRZYZANOWSKI; VIEIRA; FRANÇA NETO, 1999). Considerando apenas os teores de água, observa-se, que a redução do teor de água nas sementes, reduz possíveis danos causados durante a secagem, melhorando o desempenho fisiológico das sementes. De acordo com os resultados apresentados, observa-se que o desempenho das sementes de crambe no teste primeira contagem foi superior nas sementes com menores teores de água.

No teste de vigor que tomou a medida do comprimento das plântulas pode-se observar que a análise de variância detectou efeito significativo para temperatura, teor de água e para interação temperatura de secagem x teor de água (Tabela 4), assim como ocorrido nos dois testes anteriores.

No teste do comprimento de plântulas as variáveis significativas foram temperatura (linear e quadrática) e a interação temperatura $\mathrm{x}$ teor de água (Figura 5). Aos dados obtidos foi ajustada superfície de resposta, em que se observa que as regiões que compreendem os dois extremos da temperatura, ou seja, 30 e $70{ }^{\circ} \mathrm{C}$ são as áreas de menor desempenho no comprimento das plântulas. Sob temperatura de $50^{\circ} \mathrm{C}$ obteve-se a melhor média no comprimento das plântulas normais $-5,6 \mathrm{~cm}$. Tunes et al. (2010) estudando o fenômeno em sementes de cevada submetidas a altas temperaturas de secagem, encontraram valores semelhantes ao do crambe, em torno de $6 \mathrm{~cm}$ no comprimento das plântulas.

A avaliação da condutividade elétrica de sementes, assim como os demais testes realizados, foi influenciada também pelos fatores em estudo isoladamente e pela interação entre temperatura $\mathrm{x}$ teor de água (Tabela 5). Este teste de vigor avalia o estado das paredes celulares por meio da medição de eletrólitos presentes na água em que sementes do produto foram colocadas. Quanto maior o valor da condutividade maior o dano na semente (KRZYZANOWSKI; VIEIRA; FRANÇA NETO, 1999).

Na superfície de resposta referente à condutividade elétrica ajustou-se a interação da temperatura x teor de água, onde pode-se verificar uma microrregião representada pelos teores de água de 15 a $20 \%$ b.u em torno da temperatura de $70^{\circ} \mathrm{C}$, onde os valores da condutividade foram elevados (Figura 6), o que corresponde a um grande dano destes tratamentos nas sementes de crambe. Contudo, para os demais tratamentos há um comportamento homogêneo

Tabela 4 - Resultado da análise de variância referente ao comprimento de plântulas normais obtidas no teste de germinação, em função da temperatura do ar de secagem e dos teores de água nas sementes de crambe

\begin{tabular}{lcccc}
\hline \multicolumn{1}{c}{ Fatores } & G.L & SQ & QM & F \\
\hline Temp. de secagem (TS) & 4 & 129,853 & 32,463 & $44,478^{* *}$ \\
Teor de água (TA) & 4 & 15,269 & 3,817 & $5,230^{* *}$ \\
TS X TA & 16 & 39,853 & 2,491 & $3,413^{* *}$ \\
Resíduo & 75 & 54,740 & 0,730 & - \\
Total & 99 & 239,716 & - & - \\
\hline
\end{tabular}

**Significativo à $1 \%$ de probabilidade pelo teste F. C.V. $=6,01 \%$ 
Figura 4 - Superfície de resposta para o efeito da temperatura de secagem e teor de água em sementes de crambe, no teste de primeira contagem

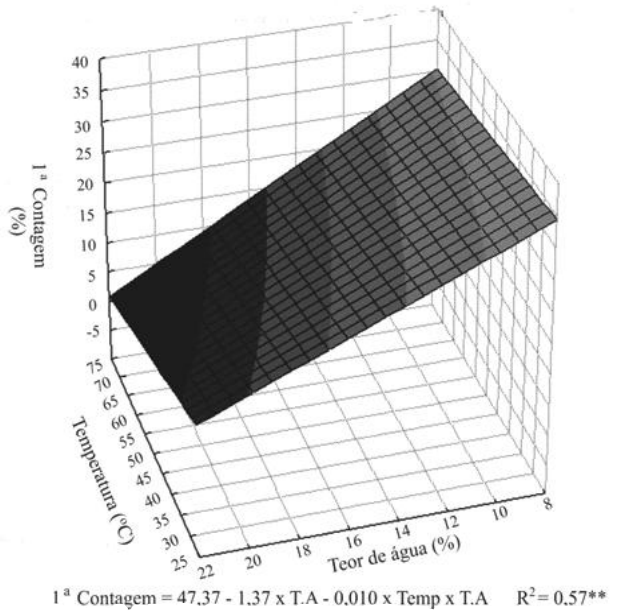

Figura 5 - Superfície de resposta para o efeito da temperatura de secagem e teor de água em sementes de crambe, no teste de comprimento das plântulas

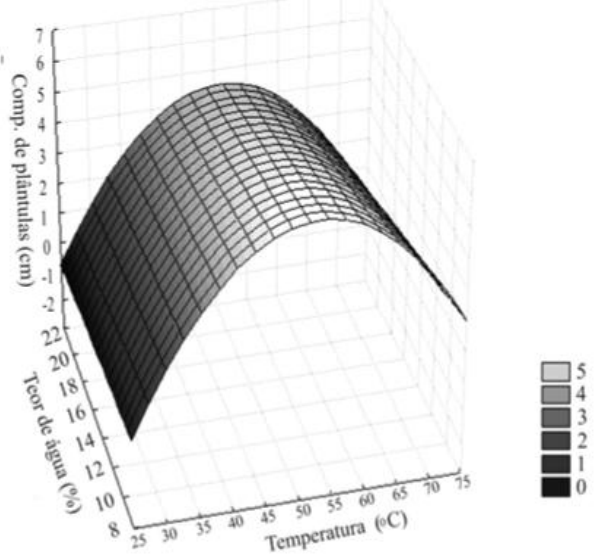

C de Plântulas $=-15,82+0,84 \times$ Temp. $-0,0078 \times$ Temp $^{2}-0,0019 \times$ Temp. $\times$ T. água $R^{2}=0,77 * *$

Tabela 5 - Resultado da análise de variância referente a leitura de condutividade elétrica em função da temperatura do ar de secagem e dos teores de água nas sementes de crambe

\begin{tabular}{lcccc}
\hline \multicolumn{1}{c}{ Fatores } & G.L & SQ & QM & F \\
\hline Temp. de secagem (TS) & 4 & 2825,46 & 706,37 & $32,225^{* *}$ \\
Teor de água (TA) & 4 & 795,36 & 198,84 & $9,071^{* *}$ \\
TS X TA & 16 & 3967,94 & 248,00 & $11,314^{* *}$ \\
Resíduo & 75 & 1644,00 & 21,92 & - \\
Total & 99 & 9232,76 & - & - \\
\hline
\end{tabular}

**Significativo à $1 \%$ de probabilidade pelo teste F. C.V. $=4,90 \%$

entre os valores, evidenciado pela menor inclinação da superfície. Os dados obtidos para as médias dos tratamentos corroboram a esta afirmativa, com valores de $186 ; 191$ e $222 \mu \mathrm{S} \mathrm{cm} \mathrm{cm}^{-1} \mathrm{~g}^{-1}$, para as temperaturas de 30,50 e $70{ }^{\circ} \mathrm{C}$ respectivamente. Vieira et al. (2002) estudaram a condutividade elétrica para soja com teores de água de 7 a 17\% b.u., encontrando valores semelhantes ao crambe, na ordem de $140 \mu \mathrm{S} \mathrm{cm} \mathrm{cm}^{-1} \mathrm{~g}^{-1}$. Gemaque et al. (2005) verificaram que a secagem de sementes de ipê roxo a 20 e $38^{\circ} \mathrm{C}$, aumentou os valores da condutividade elétrica de 80 para $114 \mu \mathrm{S} \mathrm{cm}^{-1} \mathrm{~g}^{-1}$, e concluíram que a secagem causou danos às membranas celulares devido ao aumento nos valores da condutividade, todavia, esses danos foram revertidos, em razão da qualidade fisiológica não ter sido afetada. Vale lembrar que o teste de condutividade elétrica avalia o estado das paredes celulares, mediante medição de eletrólitos presentes na
Figura 6 - Superfície de resposta para o efeito da temperatura de secagem e teor de água em sementes de crambe, no teste de condutividade elétrica

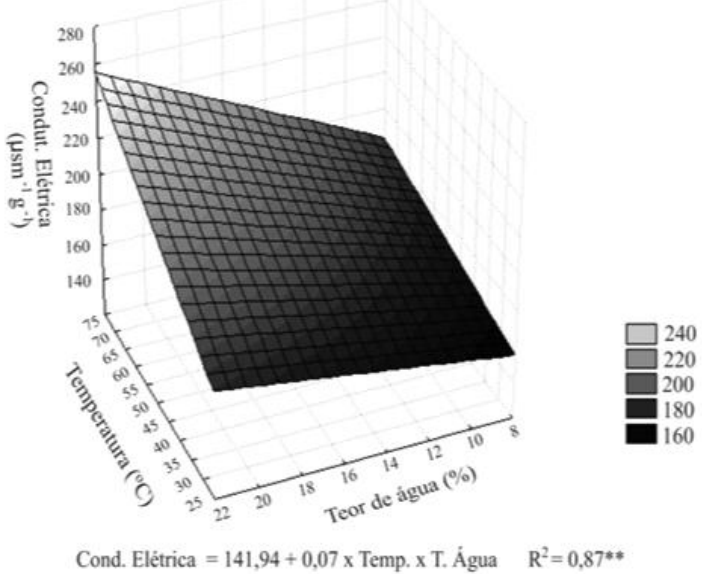


água em que sementes foram colocadas. Quanto maior o valor da leitura de condutividade, maior o dano na semente (MARCOS FILHO, 2005).

\section{CONCLUSÕES}

1.Melhor desempenho na qualidade fisiológica das sementes de crambe é obtido com teores de água abaixo de $15 \%$, secas às temperaturas acima de $50{ }^{\circ} \mathrm{C}$. Em contrapartida, temperaturas acima de $50{ }^{\circ} \mathrm{C}$, associadas a teores de água acima de $15 \%$, promoveu danos significativos à qualidade das sementes;

2. Temperaturas de secagem acima de $60{ }^{\circ} \mathrm{C}$ atua positivamente na quebra de dormência das sementes de crambe, com baixos teores de água.

\section{AGRADECIMENTOS}

À Capes pela concessão da bolsa de mestrado à primeira autora e ao $\mathrm{CNPq}$ pelo financiamento da pesquisa.

\section{REFERÊNCIAS}

BITTENCOURT, E. Biodiesel: matéria prima - crambe tem alto potencial: oleaginosa pode ser produzida em larga escala e a baixo custo no período de safrinha. Canal Jornal da Bioenergia, v. 4, n. 46, s/p. 2010. Disponível em: <http://www.canalbioenergia.com.br/files/revista/ ebqorigqtxpwbqhuvjokiclzerujws.pdf.> Acesso em: 30 abr. 2012

BRASIL. Ministério da Agricultura e Reforma Agrária. Secretaria Nacional de defesa Agropecuária. Regras para análise de sementes. Brasília, 2009. 395 p.

CÂMARA, G. M. S.; HEIFFIG, L. S. Agronegócio de plantas oleaginosas: matérias-primas para biodiesel. Piracicaba: Esalq, 2006. 96 p. v. 1.

CARVALHO, N. M.; NAKAGAWA, J. Sementes: ciência, tecnologia e produção. 4. ed. Jaboticabal: FUNEP, 2000. 588 p.

COLODETTI, T. V. et al. Crambe: aspectos gerais da produção agrícola. Enciclopédia Biosfera, v. 8, n. 14, p. 258-269, 2012.

CORRÊA, P. C. et al. Modelagem matemática para a descrição do processo de secagem do feijão (Phaseolus vulgaris L.) em camadas delgadas. Engenharia Agrícola, v. 27, n. 2, p. 501-507, 2007.

COSTA, L. M. et al. Isotermas de dessorção e calor isostérico dos frutos de crambe. Revista Brasileira Engenharia Agrícola e Ambiental, v. 17, n. 4, p. 412-418. 2013.

COSTA, L. M. et al. The influence of drying on the physiological quality of crambe fruits. Acta Scientiarum Agronomy, v. 34, n. 2, p. 213-218, 2012.
COSTA, F. P.; MARTINS, L. D.; LOPES, J. C. Frequência de germinação de sementes de crambe (Crambe abyssinica Hochst.) sob influência de tratamentos pré-germinativos e de temperaturas. Nucleus, v. 7, n. 2, p. 185-193, 2010.

FARIA, R. Q. et al. Cinética de secagem de sementes de crambe. Revista Brasileira de Engenharia Agrícola e Ambiental, v. 16, n. 5, p. 573-583, 2012.

GEMAQUE, R. C. R. et al. Efeito das secagens lenta e rápida em sementes de ipê-roxo (Tabebuia impetigino (Mart.) Standl.). Revista Cerne, v. 11, n. 4, p. 329-335, 2005.

KRZYZANOWSKI, F. C.; VIEIRA, R. D.; FRANÇA NETO, J. B. Vigor de sementes: conceitos e testes. Londrina: ABRATES, 1999. $218 \mathrm{p}$.

MARCOS FILHO, J. Fisiologia de sementes de plantas cultivadas. Piracicaba: Fealq, 2005. 495 p.

MARTINS et al. Influence of pre-germination treatments and temperature on the germination of crambe seeds(Crambe abyssinica Hochst). Idesia, v. 30, n. 3, p. 23-28, 2012.

NEVES, M. B. et al. Qualidade fisiológica de sementes de crambe produzidos em Mato Grosso do Sul. In: SIMPÓSIO ESTADUAL DE AGROENERGIA, 2007, Pelotas, RS. Anais... Pelotas, RS: EMBRAPA, 2007. p. 97-98.

PITOL, C.; BROCH, D. L.; ROSCOE, R. Tecnologia e produção: crambe. Maracaju: Fundação MS, 2010. 60 p.

RESENDE, O. et al. Modelagem matemática e difusidade efetiva das sementes de pião-manso (Jatropha curcas L.) durante a secagem. Revista Engenharia Agrícola, v. 31, n. 6, p. 1123-1135, 2011.

RUAS, R. A. A. et al. Embebição e germinação de sementes de crambe (Crambe abyssinica). Pesquisa Agropecuária Tropical, v. 40, n. 1, p. 61-65, 2010.

SOUZA, A. D. V. et al. Caracterização química de sementes e tortas de pinhão-manso, nabo-forrageiro e crambe. Pesquisa Agropecuária Brasileira, v. 44, n. 10, p. 1328-1335, 2009.

SPRENT, P.; SMEETON, N. C. Applied nonparametric statistical methods. Boca Raton: Chapman \& Hall, 2007. 530 p.

STEEL, R. G. D.; TORRIE, J. H.; DICKEY, D. A. Principles and procedures of statistics: a biometrical approach. New York: McGraw-Hill, 1997. 666 p.

TRZECIAK, M. B. et al. Utilização de sementes de espécies oleaginosas para produção de biodiesel. Informativo Abrates, v. 18, n. 1/3, p. 30-38, 2008.

TUNES, L. M. et al. Armazenabilidade de sementes de cevada colhidas em diferentes épocas. Bioscience Journal, v. 26, n. 3 , p. 403-412, 2010.

VANZOLINI, S. et al. Teste de comprimento de plântula na avaliação da qualidade fisiológica de sementes soja. Revista Brasileira de Sementes, v. 29, n. 2, p. 90-96, 2007.

VIEIRA, R. D. et al. Condutividade elétrica e teor de água inicial das sementes de soja. Pesquisa Agropecuária Brasileira, v. 37, n. 9, p. 1333-1338, 2002. 